\title{
Technology Incorporation in Primary Teeth Endodontics: Case Reports
}

\author{
Luana AS Gomes ${ }^{1}$, Amanda A Oliveira ${ }^{2}$, Ana TS de Campos Neves ${ }^{3}$, Andreza M Aranha ${ }^{4}$, Luiz ER Volpato ${ }^{5}$
}

\begin{abstract}
Background: Radical pulp therapy is an important and a relatively frequent procedure in pediatric dental offices. Aim: This study presents two clinical cases of pulpectomies in deciduous teeth using electronic apex locator and rotary instrumentation. Case descriptions: In Case 1, pulpectomy was performed in a deciduous incisor with diagnosis of pulp necrosis in a 3-year-old patient using an electronic apical locator and manual instrumentation. In Case 2, it was performed in a primary molar with diagnosis of irreversible acute pulpitis in a 9-year-old patient with the use of electronic apical locator and rotational instrumentation. The used technologies contributed to favorable final result of the endodontic treatments in deciduous teeth in both cases.

Conclusion: The incorporation of technology to the endodontic treatment of primary teeth favored the gain of time and conicity of the root canal preparation. However, studies still need to be performed to consolidate the technique.

Clinical significance: Endodontic treatment of primary teeth still generates much discussion about the materials and techniques employed. The use of electronic apical locator and rotational instrumentation is successful treatment alternatives for teeth with pulp necrosis, with the advantage of limiting clinical time and presenting a favorable outcome.

Keywords: Deciduous, Pulpectomy, Pulp capping and pulpectomy agents, Tooth.

International Journal of Clinical Pediatric Dentistry (2020): 10.5005/jp-journals-10005-1719
\end{abstract}

\section{BACKGROUND}

Despite the advance in the prevention of dental caries and the consequent decrease in its incidence, the number of teeth with deep caries that end up compromising pulp vitality is still high, and endodontic treatment is indicated. ${ }^{1}$ Traumatized primary teeth may also have pulp necrosis as sequelae requiring radical endodontic treatment. $^{2}$

Root canal instrumentation can be facilitated by the efficient use of automated systems, especially in ducts that are difficult to access with hand instruments. Advantages include better duct cleaning and shaping, which promotes a more even paste filling. Disadvantages may include equipment cost and the skills needed to become skilled with the techniques. ${ }^{3}$

The pulpectomy procedure in deciduous molars with automated method reduces the clinical time. In addition, the quality of the obturation is more acceptable than by the conventional method. $^{4}$

One of the main goals of pediatric dentistry is to maintain the deciduous teeth until the normal exfoliation period so that the arch perimeter, function, esthetics, and phonetic are maintained. Using these endodontic technologies in primary teeth, a great advance is seen in the improvement of technical quality and a substantial gain of time in the procedure, which consequently reflects in the better behavior of the infant patient.

As endodontic treatment of primary teeth still generates much discussion regarding the materials and techniques employed, it is justified to present clinical cases of infantile patients using rotary instrumentation and the use of apical locator assessing the benefits and difficulties in performing the techniques. Thus, the aim of this paper was to present two clinical cases using rotary instrumentation and electronic apex locator.

\author{
${ }^{1}$ Mirassol D'Oeste, MT, Brazil \\ ${ }^{2-5}$ Dental School, University of Cuiabá, Cuiabá, MT, Brazil
}

Corresponding Author: Luiz ER Volpato, Dental School, University of Cuiabá, Cuiabá, MT, Brazil, Phone: +55 6536221538, e-mail: odontologiavolpato@uol.com.br

How to cite this article: Gomes LAS, Oliveira AA, de Campos Neves ATS, et al. Technology Incorporation in Primary Teeth Endodontics: Case Reports. Int J Clin Pediatr Dent 2020;13(2):180-185.

Source of support: Nil

Conflict of interest: None

\section{Case Descriptions}

\section{Case 1}

A 3-year-old male patient presented to a pediatric dental clinic. His main complaint was a broken front tooth and a temporary filling of the tooth for which the root canal treatment had not been finished. As a result, the child's face had already been swollen with pain getting aggravated. The mother also reported previous unfinished dental treatment. During the anamnesis, the child was found to have good overall health, absence of systemic diseases, or allergies and did not use any medication. The child received breastfeeding until about one year of age. His diet was cariogenic, and during clinical examination, poor oral hygiene and extensive coronary destruction were observed in teeth 52, 51, and 61 (Fig. 1). In the posterior teeth, the patient presented carious lesions in teeth $64,65,74,75,84$, and 85.

Radiographic examination (Fig. 2) was performed with positioner using molt opener and under protective stabilization using the pediatric sheet. As the young patient did not exhibit

() The Author(s). 2020 Open Access This article is distributed under the terms of the Creative Commons Attribution 4.0 International License (https://creativecommons. org/licenses/by-nc/4.0/), which permits unrestricted use, distribution, and non-commercial reproduction in any medium, provided you give appropriate credit to the original author(s) and the source, provide a link to the Creative Commons license, and indicate if changes were made. The Creative Commons Public Domain Dedication waiver (http://creativecommons.org/publicdomain/zero/1.0/) applies to the data made available in this article, unless otherwise stated. 


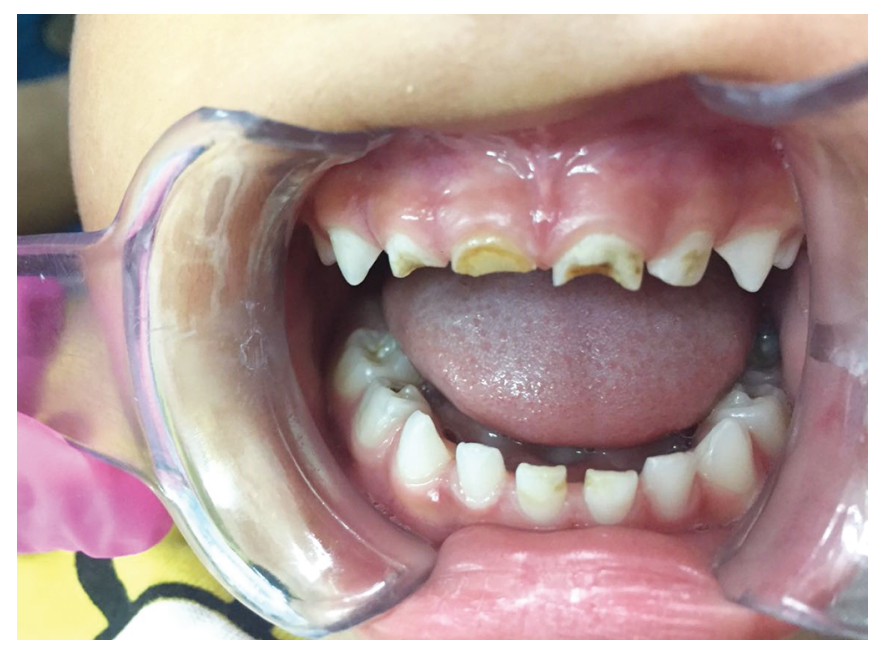

Fig. 1: Initial image showing severe carious lesions in teeth 52, 51, and 61

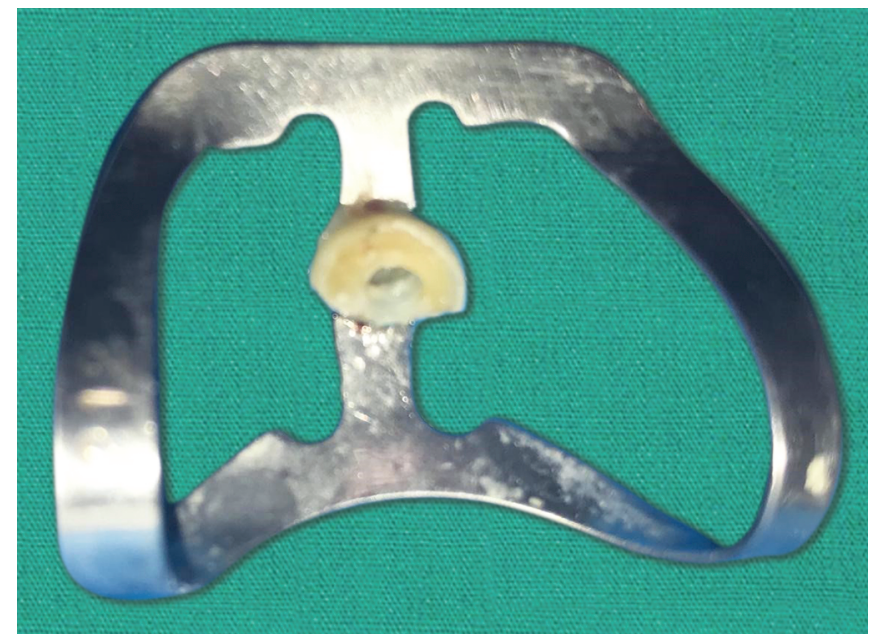

Fig. 3: Crown opening of tooth 51

good behavior, protective stabilization was necessary. Radiographic image revealed that tooth 51 had temporary material in pulp chamber, and there was no increase in ligament space nor periapical lesion.

Treatment planning for tooth 51 consisted of single-session necropulpectomy and subsequent installation of fiberglass post and restoration with resin in acetate crown.

The patient was then anesthetized by the infiltrative technique using $12 \%$ lidocaine 1:100,000 tube with epinephrine and absolute isolation of tooth 51 with clamp No. 212 (Duflex-SS White) was performed and coronary access was performed with spherical drill 1,014 in high rotation (Fig. 3).

The cervical third was prepared using the Gates-Glidden Drill (Dentsply Maillefer, Ballaigues, Switzerland) No. 21 of $21 \mathrm{~mm}$. Throughout the canal instrumentation, irrigation with $1 \%$ sodium hypochlorite was performed.

Subsequently, excess fluid was removed from the pulp chamber and the electronic measurement was obtained through the Apex Electronic Locator J2 (APTS, Guangdong, China). The channel measurement was $14 \mathrm{~mm}$ (Fig. 4).

The instrumentation was done by hand technique with K-type files (Denstply-Sirona, Pirassununga, SP, Brazil), crown-apex sense.

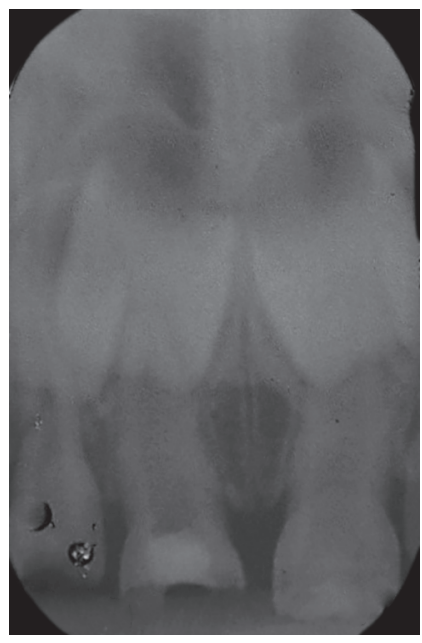

Fig. 2: Initial radiography of tooth 51 with image of temporary material overlying the pulp chamber and absence of enlargement in the ligament space nor periapical lesion

(50LK, 45LK and 40LK). The final EDTA Toilet (Biodynamics, Ibiporã, PR, Brazil) was made for three minutes under shaking with a hand file. Again the canal was irrigated with $1 \%$ sodium hypochlorite (Fig. 5). The canal was then dried with absorbent paper tips (Tanari, Manacapuru, AM, Brazil) of a caliber compatible with the last file used in the instrumentation.

To complete the procedure, the root canal was filled with iodoform paste (Fig. 6), which was taken into the canal with a manual file (Figs 7 to 9).

In another session, a Meron-cemented fiberglass post (VOCO, Cuxhaven, Germany) was installed, and a composite resin crown was made using an acetate matrix using Empress composite resin (IVOCLAIR Vivadent AG, Liechtenstein), in dentin A1 color (Fig. 10).

\section{Case 2}

Male patient, 9-years-old, attended the pediatric dental clinic, with the complaint of spontaneous pain in the lower region of the face on the right side. The patient's responsible reported that he was taking analgesic medication without professional guidance. The pain was reported to be exacerbated during the night prior to the consultation.

In the anamnesis, good general health was confirmed. Patient had mixed dentition. There were no changes in soft tissue. He had good oral hygiene at the time of consultation. Guidance was given on oral hygiene and a proper diet.

Radiographic examination was performed by means of radiographic positioner (Fig. 11).

The patient was then anesthetized by the inferior alveolar technique with $12 \%$ lidocaine 1:100,000 tube with epinephrine. Absolute isolation was made with clamp No. 27 (Duflex), Young's folding arch (Angelus), and rubber sheet (Madeitex, São José dos Campos, SP, Brazil).

The diagnosis of the case was confirmed as irreversible acute pulpitis. After coronary opening, the macroscopic aspect of the pulp was bright red in color, with intense bleeding, which made difficult to cut with endodontic curette. An attempt was made to stop the bleeding with formocresol (Maquira, Maringá, PR, Brazil) five minutes in a cotton ball for pulpotomy, but even after the 

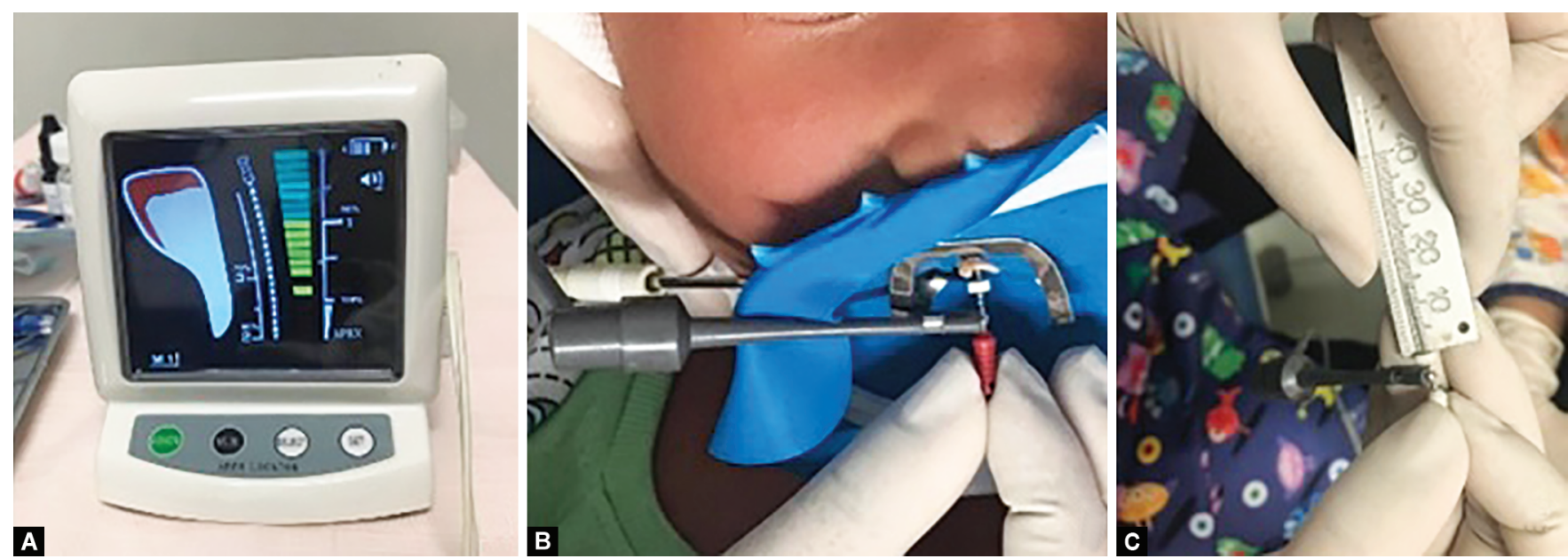

Figs 4A to C: (A) Electronic apex locator; (B) Electronic measurement being performed through the apex locator; (C) Measure of manual file

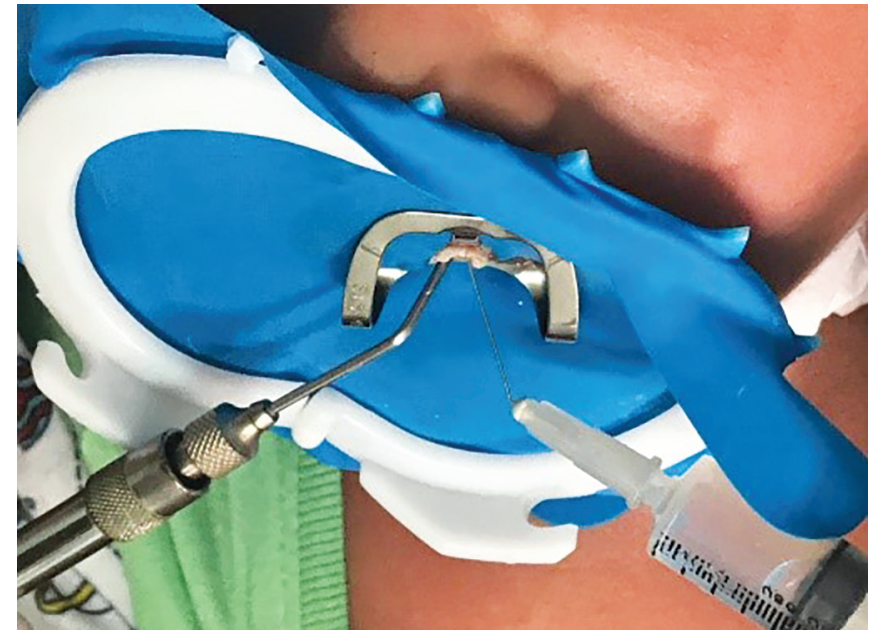

Fig. 5: Irrigation with $1 \%$ sodium hypochlorite, with disposable syringe and needle and aspiration cannula

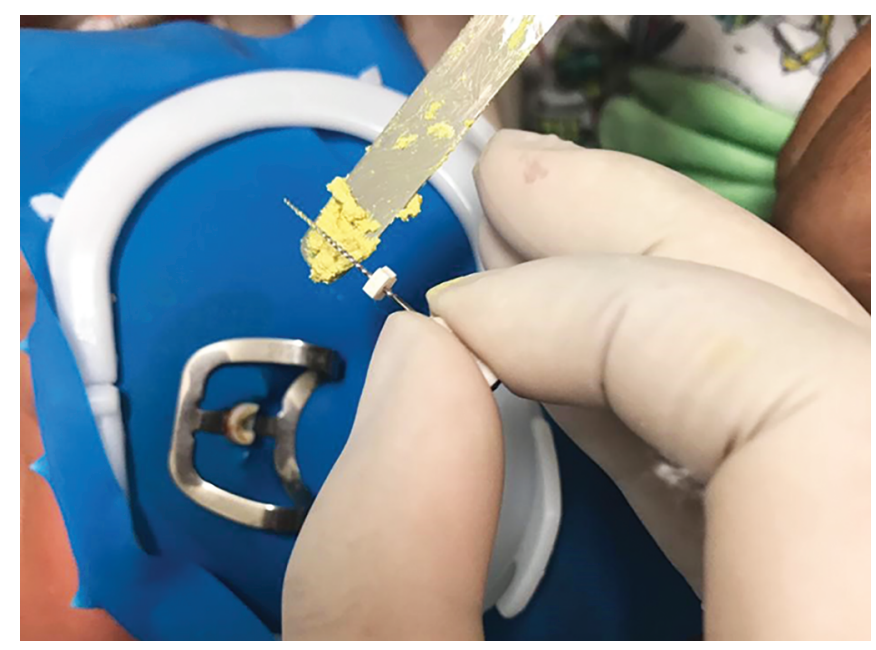

Fig. 7: Beginning of canal obturation with the aid of a manual file

5 minutes period with the dressing, the pulp did not stop bleeding, thus leading to radical endodontic treatment (biopulpectomy).

The coronary opening was made with a 1,014 drill at high rotation, and the coronary pulp was removed with curette no. 11/12

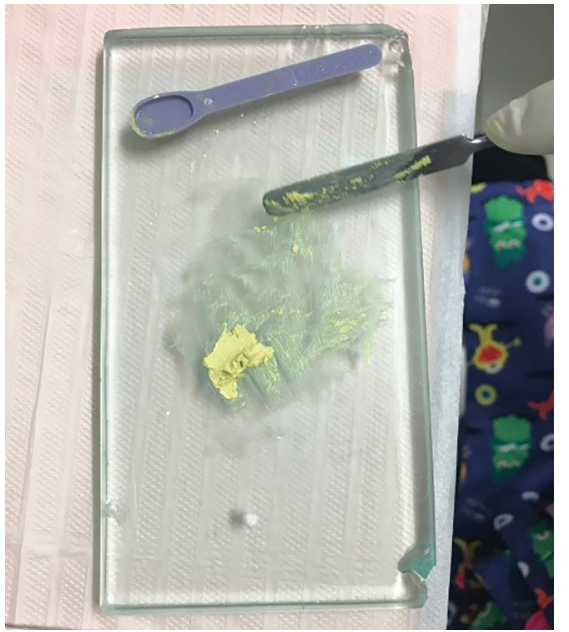

Fig. 6: Appearance of the iodoformed paste after spatulation

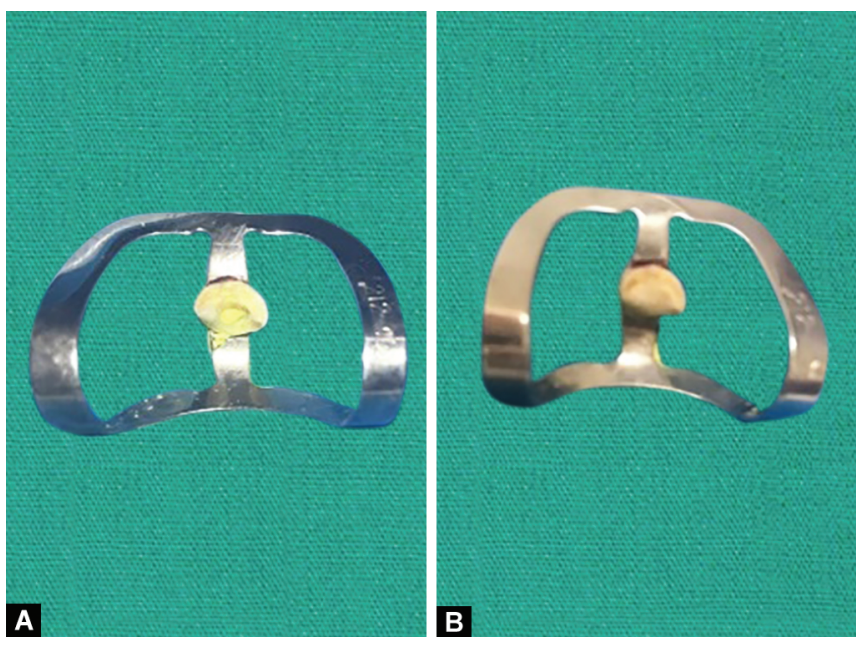

Figs $8 \mathrm{~A}$ and $\mathrm{B}$ : (A) After the channel is completely filled with the iodoformed paste; (B) Final image after coronary shielding with resinmodified glass ionomer cement

(Maillefer SARL, Switzerland). Throughout the instrumentation, the irrigation was abundant with saline solution. The canals were mapped with K\# 10 files (Denstply Sirona, Pirassununga, São Paulo, 

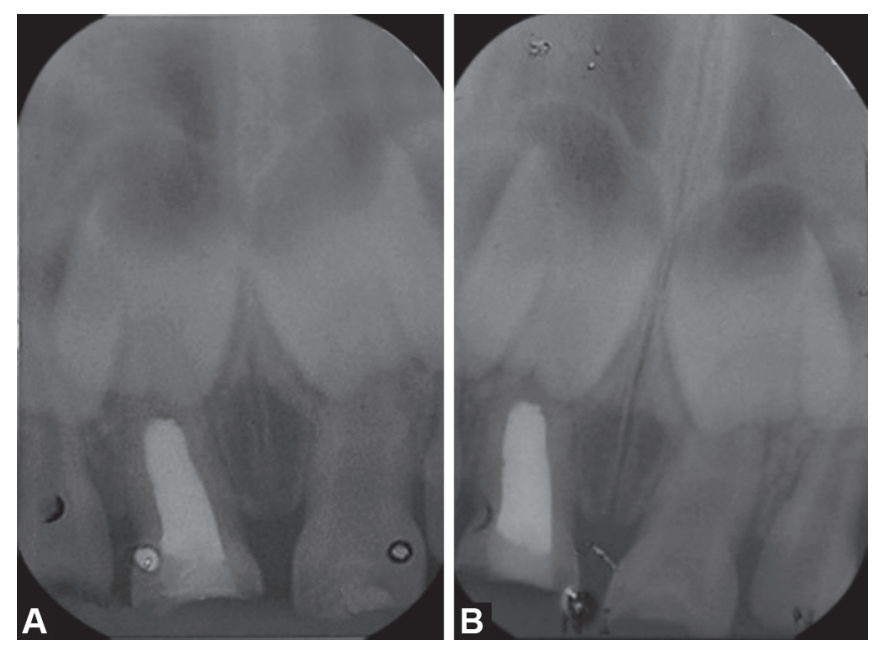

Figs $9 A$ and B: (A) Radiograph immediately after obturation of element 51 with iodoform paste and resin-modified Civ coronary shielding; (B) Follow-up radiograph after 90 days

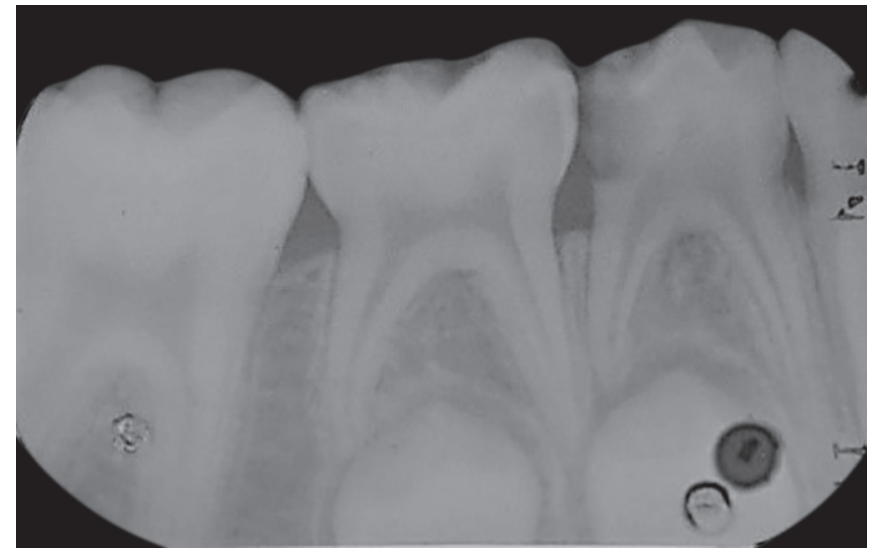

Fig. 11: Initial image tooth 84 with occlusal-distal caries overlapping the pulp chamber image, with no interradicular lesion and periodontal ligament enlargement

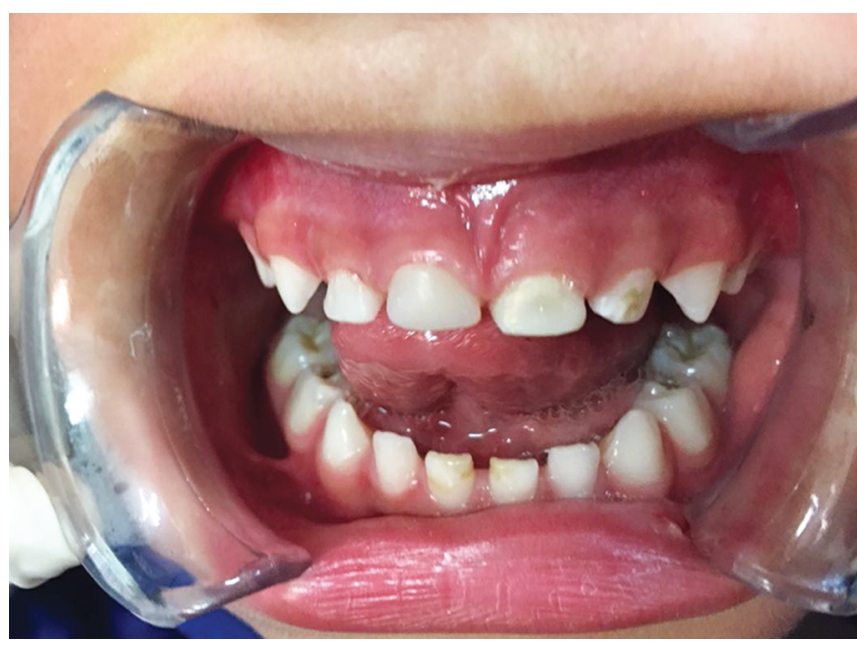

Fig. 10: Final image: After pulpectomy on tooth 51, a fiberglass post was installed and a direct composite resin crown was installed. In teeth 52 and 61, only a direct resin crown was performed without pulp therapy

Brasil). The cervical third was prepared with Gates-Glidden No. 01 drills (Maillefer SARL, Switzerland) at low rotation.

After bleeding control, the electronic apex locator (Apex Locator J2-Sofedent-China) was used for the electronic measurement. The measurements obtained were as follows: $\mathrm{MV}=13 \mathrm{~mm} ; \mathrm{ML}=12$ $\mathrm{mm}$; and $\mathrm{D}=12 \mathrm{~mm}$.

From then on, the instrumentation was performed with the X-Smart Dentsply Electric Motor (Dentsply Maillefer, Japan) using Protaper Universal files (Dentsply Maillefer, Ballaigues, Switzerland) (Fig. 12). The mesial canals were instrumented to the F1 file and the distal to the F3 file.

The canals were irrigated again and the final toilet made with EDTA (Biodynamics, Ibiporã, Paraná, Brazil) for three minutes under agitation with lentulo \# 25 drill (Denstply Sirona, Pirassununga, São Paulo, Brazil) at low rotation. Again, the saline was irrigated and the canals were dried with absorbent paper tips of caliber compatible with the last lime used in the preparation.

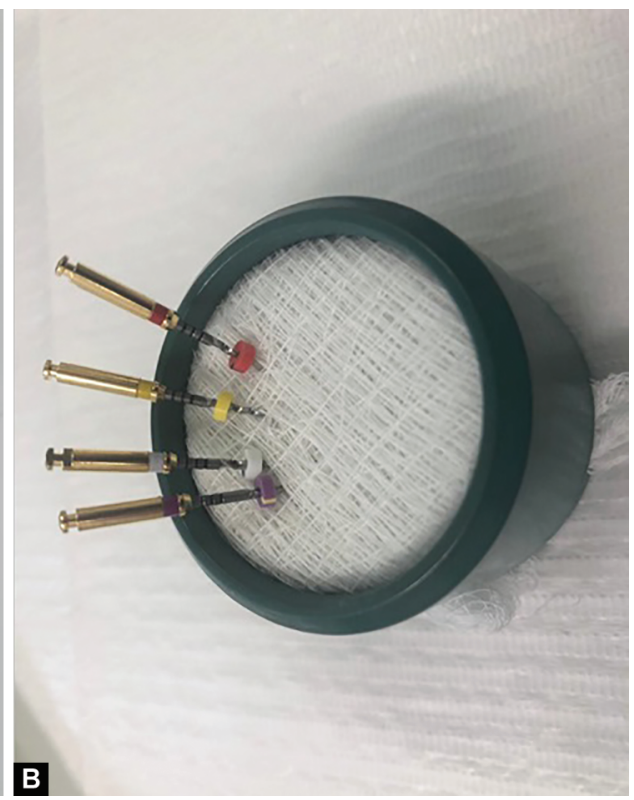

Figs 12A and B: (A) X-Smart Dentsply Electric Motor (Maillefer, Japan); (B) Protaper Universal Rotary Files (Dentsply Maillefer, Ballaigues, Switzerland) 


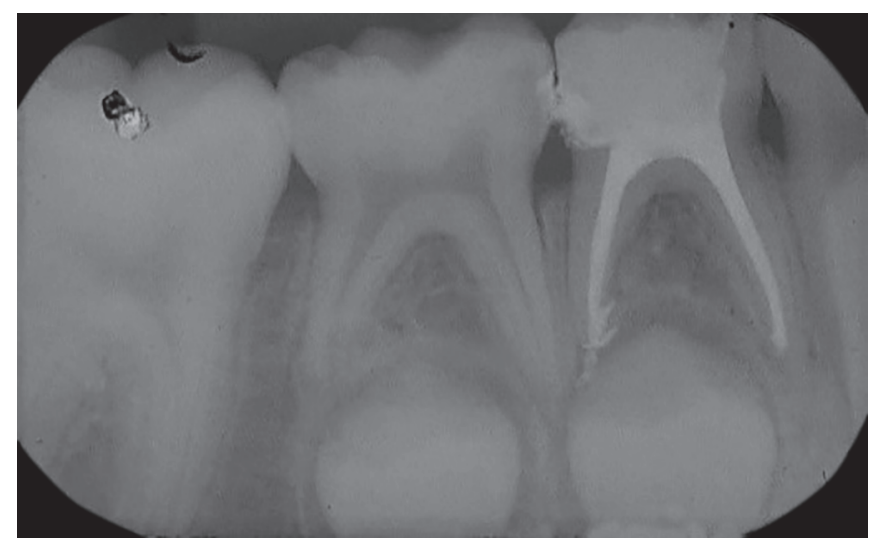

Fig. 13: Radiograph of tooth 84, after obturation with radiopaque aspect of iodoform paste, with slight leakage of obturator material in the distal root, and coronary chamber filled with resin-modified glass ionomer cement

To finish the case, the canals were filled with iodoform paste being carried into the root canals with the aid of lentulo no. 25 drill (Denstply Sirona, Pirassununga, São Paulo, Brazil), in a low clockwise rotation.

The coronary portion was shielded with Riva resin-modified glass ionomer cement (SDI, Victoria, Australia), absolute isolation was removed, and occlusion was verified.

The final radiograph (Fig. 13) was obtained by radiographic positioner (Angelus) and radiographic film (Kodak).

\section{Discussion}

One of the greatest challenges of pediatric dentistry is maintaining the primary teeth in the arch until their normal exfoliation time. Teeth with severe tooth decay and traumatized teeth with irreversible pulp changes need a radical endodontic treatment to continue their functions, such as esthetics, phonetic, chewing, and maintenance of the arch perimeter. ${ }^{1}$ In Case 1, the patient had severe childhood caries, which caused pulp necrosis in element 51 , and the coronary destruction of this tooth affected the patient's esthetics. In Case 2, the function was compromised as the affected tooth presented painful symptoms with chewing, making the child's feeding difficult.

The introduction of motor-driven files made from nickeltitanium alloy was a major development in root canal preparation. Several studies have evaluated the efficiency of cleaning manual and automated files on permanent molars. However, few studies have been performed on primary molars. ${ }^{5}$ In Case 2, the use of automated instrumentation provided a tapered preparation channel, easily filled by the obturator paste. It is time-saving, as the patient presented at the clinic late in the morning, and yet, within a short time, his treatment was successfully completed in a single session.

The main disadvantage of the automated system is the high cost of equipment and previous operator training, as the technique is more complicated compared with the manual technique., ${ }^{1,6}$ This disadvantage was overcome in the cases described because the professional also works as an endodontist and already had the equipment. Currently, many universities have already implemented the automated technique in undergraduate endodontics. And there are a wide variety of brands and values of apex locators and engines on the market, which increases access to these technologies by more professionals.
The use of apex locator in children also shows advantage over conventional radiography, because it does not use ionizing radiation, and it is not necessary to use intraoral films. It safely measures even channels where the rhizolysis process has already started. The conventional technique using radiographs has the disadvantages: Its accuracy depends on the child's cooperation, and the radiographic image may be ambiguous because of overlapping anatomical structures and small areas of resorption may not be seen. ${ }^{7}$ In both cases, the use of the apex locator was positive, since roots with rhizolysis process already started are not always visible on conventional radiography, as it is a two-dimensional examination, image overlays can reveal false images, and areas of resorption by the rhizolysis process may be imperceptible on radiography. Without the locator, these channels could become over-inflicted, a negative factor during endodontic treatment.

Endodontics in pediatric dentistry has been modernizing, and much research should be conducted in search of new evidence for the consolidation of automated treatment in primary teeth. $^{8}$

The use of these technologies in both cases proved to be effective, with several positive aspects, being reduced working time, lower patient stress, and greater professional comfort, as manual instrumentation causes operator discomfort over time for the repetitive movements. Regarding the electronic measurement, the apical locator brought more security to work in a safe working length, avoiding overinstrumentation and its consequences. In Case 2, which was instrumented with rotary files, the canal became quite conical and easily filled with the obturator paste, where it easily filled the root canal, leading to quality shutter at optimal working length.

\section{Conclusion}

Radical pulp therapy is a very important procedure in pediatric dentistry, where its performance is the last recourse for the maintenance of pulp-altered teeth in the child's dental arch. In the cases presented, it was verified that the new technologies only positively aggregate to the endodontic treatments in primary teeth. In the automated technique, it is noted an excellent performance regarding the time gain and conicity of the preparation. However, studies must still be performed to consolidate the technique in pediatric dental patients.

\section{Clinical Significance}

Automated endodontic treatment can be considered as a treatment option for teeth with pulp necrosis, with the advantage of limiting clinical time.

\section{References}

1. Mokhtari N, Shirazi AS, Ebrahimi M. A smart rotary technique vs conventional pulpectomy for primary teeth: a randomized controlled clinical study. J Clin Exp Dent 2017;9(11):e1292-e1296. DOI: 10.4317/ jced.53968.

2. Moccelini BS, de Alencar NA, Bolan M, et al. Pulp necrosis and crown discoloration: a systematic review and meta-analysis. Int J Paediatr Dent 2018. DOI: 10.1111/ipd.12372.

3. Moghaddam KN, Zadeh HF, Zadeh NF. Comparison of cleaning Efficacy and instrumentation time of Reciproc and Mtwo rotary systems in primary molars. J Islam Dent Assoc Iran 2017;1(29):15-20. DOI: 10.30699/jidai.29.1.15. 
4. Makarem A, Rvavandeh N, Ebrahimi M. Radiographic assessment and chair time of rotary instruments in the pulpectomy of primary Second molar teeth: a randomized controlled clinical trial. J Dent Res Dent Clin Dent Prospects 2014;2(8):84-89.

5. Ramezanali F, Afkhami F, Soleimani A, et al. Comparison of cleaning Efficacy and instrumentation time in primary molars: Mtwo rotary instruments vs hand K-files. Iran Endod J 2015;10(4):240-243.

6. Barr ES, Kleier DJ, Barr NV. Use of nickel-titanium rotary files for root canal preparation in primary teeth. Pediatr Dent 1999;21(7):453-454.
7. Bahrololoomi Z, Soleymani AA, Modaresi J, et al. Accuracy of na electronic apex locator for working length determination in primary anterior teeth. J Dent (Tehran) 2015;12(4): 243-248.

8. Jeevanandan G, Govindaraju L. Clinical comparison of Kedo-S paediatric rotary files vs manual instrumentation for root canal preparation in primary molars: a double blinded randomised clinical trial. Eur Arch Paediatr Dent 2018;19(4):273-278. DOI: 10.1007/s40368018-0356-6. 